\title{
Ductal stenting retrains the left ventricle in transposition of great arteries with intact ventricular septum
}

\author{
Kothandam Sivakumar, MD, DM, ${ }^{\mathrm{a}}$ Edwin Francis, MD, DM, ${ }^{\mathrm{a}}$ Prasad Krishnan, MS, $\mathrm{MCh}^{\mathrm{b}}{ }^{\mathrm{b}}$ and Jagdish Shahani, $\mathrm{MD}^{\mathrm{b}}$
}

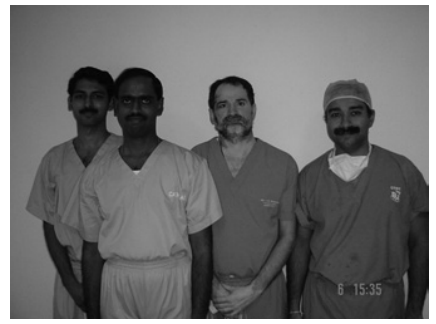

Drs Francis, Sivakumar, Shahani, and Krishnan (left to right)
Objective: In late presenters with transposition of the great arteries, intact ventricular septum, and regressing left ventricle, left ventricular retraining by pulmonary artery banding and aortopulmonary shunt is characterized by a stormy postoperative course and high costs. Ductal stenting in the cardiac catheterization laboratory is conceptualized to retrain the left ventricle with less morbidity.

Methods: Recanalization and transcatheter stenting of patent ductus arteriosus was performed in patients with transposition to induce pressure and volume overload to the regressing left ventricle. Serial echocardiographic monitoring of left ventricular shape, mass, free wall thickness, and volumes was done, and once the left ventricle was adequately prepared, an arterial switch was performed. The ductal stent was removed and the remaining surgical steps were similar to a 1-stage arterial switch operation. Postoperative course, need for inotropic agents, and left ventricular function were monitored.

Results: Ductal stenting in 2 patients aged 3 months resulted in improvement of indexed left ventricular mass from 18.9 to $108.5 \mathrm{~g} / \mathrm{m}^{2}$, left ventricular free wall thickness from 2.5 to $4.8 \mathrm{~mm}$, and indexed left ventricular volumes from 7.6 to 29.5 $\mathrm{mL} / \mathrm{m}^{2}$ within 3 weeks. Both patients underwent arterial switch (bypass times 125 and 158 minutes) uneventfully, needed inotropic agents and ventilatory support for 3 days, and were discharged in 8 and 10 days.

Conclusions: Ductal stenting is a less morbid method of left ventricular retraining in transposition of the great arteries with regressed left ventricle. Its major advantages lie in avoiding pulmonary artery distortion and neoaortic valve regurgitation resulting from banding and also in avoiding thoracotomy.

I $\mathrm{n}$ infants with transposition of the great arteries with intact ventricular septum (TGA-IVS) and regressed left ventricle (LV) presenting beyond 2 months of age, pulmonary artery (PA) banding and aortopulmonary shunt is a necessary step for LV retraining before the arterial switch operation (ASO). ${ }^{1,2}$ The regressed LV appears on the echocardiogram as a banana-shaped, squashed chamber with interventricular septum bowing into the LV cavity, reduced LV volumes, thinned free wall, and reduced LV mass. ${ }^{3}$ This preparatory stage (PA band and shunt) of the 2-stage approach is associated with a stormy postoperative course and prohibitive costs, especially in the developing world, and on long-term follow-up, impaired LV mechanics and increased incidence of neoaortic regurgitation. ${ }^{4-6}$ We conceptualized a nonsurgical option for $\mathrm{LV}$ retraining by dilatation and stenting of the patent ductus arteriosus (PDA) in the cardiac catheterization laboratory to provide pressure and volume overload to the regressing LV. If this results in demonstrable improvement of LV mass, free wall thickness, and shape change in patients with TGA-IVS and regressed LV, this might offer a less morbid alternative than PA banding and aortopulmonary shunt. In addition, avoiding thoracotomy maintains a virgin chest and might facilitate smooth conduct of subsequent ASO. 

Abbreviations and Acronyms
ASO $=$ arterial switch operation
IVS $=$ intact ventricular septum
$\mathrm{LV}=$ left ventricle (ventricular)
$\mathrm{PA}=$ pulmonary artery
PDA $=$ patent ductus arteriosus
$\mathrm{RV}=$ right ventricle (ventricular)
TGA $=$ transposition of the great arteries

\section{Patients and Methods \\ Study Setting}

The study was conducted in a tertiary referral center in Srilanka, which performs most of the neonatal cardiac operations in the island. All infants presenting with TGA-IVS at less than 2 months of age were offered primary ASO irrespective of the echocardiographic appearance of the LV, even if there were features of low LV pressures. However, in infants presenting beyond 2 months of age with a banana-shaped or squashed LV on the echocardiogram, recanalization and stenting of the PDA was offered as a way of LV retraining. These infants were included in the study.

\section{Echocardiographic Evaluation}

All patients with TGA-IVS were evaluated by echocardiography for the preparedness of the LV with a GE Vivid 7 ultrasound machine (Chalfont St Giles, United Kingdom) using a broad-band 5S harmonic imaging probe under conscious sedation. Diastolic and systolic phases of the cardiac cycle were identified by with chloral and electrocardiographic gating. LV indices of interest were LV end-diastolic thickness of the posterior free wall in the parasternal view, LV end-diastolic and end-systolic volumes and ejection fractions measured by the modified biplane Simpson method in the apical view, and LV mass assessed by the arealength method after endocardial and epicardial border digitization of the LV margins, averaged from 3 cardiac cycles. ${ }^{7}$ Appearance of the LV (banana-shaped on apical view) and relative position of the interventricular septum in end-systole (bowing of the septum into the LV) were also noted as evidence of low LV pressures. ${ }^{8}$ High parasternal long-axis view and suprasternal views showed the presence of flows across the PDA and, if there were no color Doppler flows, the presence of a ductal ampulla on the anterior surface of the aortic isthmus was noted. The adequacy of intercirculatory mixing across a patent foramen ovale determined the need for a balloon atrial septostomy.

\section{Cardiac Catheterization and PDA Stenting}

Informed consent was obtained for PDA stenting and institutional review board approval was obtained. Under conscious sedation of the patient with ketamine, $5 \mathrm{~F}$ introducer sheaths were introduced into the femoral vein and artery, and balloon septostomy was performed with a Rashkind septostomy catheter (Medtronic, Inc, Minneapolis, Minn). Heparinization was done with one dose of 100 units $/ \mathrm{kg}$. A balloon-tipped Berman angiographic catheter (Arrow International, Inc, Reading, $\mathrm{Pa}$ ) was advanced from the venous sheath through the foramen ovale into the LV and another arterial catheter was advanced into the right ventricle (RV). Simultaneous
RV and LV systolic pressures were thereby measured. If the $\mathrm{LV} / \mathrm{RV}$ pressure ratio was less than 0.5 , an aortogram was done in the lateral view to view the ductal ampulla and assess patency of the duct. If there was a restrictive PDA with flows, a 0.014-inch coronary guidewire was advanced through a $5 \mathrm{~F}$ right coronary Launcher guiding catheter (Medtronic, Inc) and a 3.5- to 4-mm short coronary stent was deployed across the restrictive PDA to stent open the duct. ${ }^{9}$ If there was no ductal patency, the ductal ampulla was probed with a 0.035 -inch Terumo guidewire (Terumo Heart, Inc, Tokyo, Japan) to gain entry into the PA through the PDA, and then PDA was stented as described above. During the procedure, continuous monitoring of the LV pressures assessed changes in $\mathrm{RV} / \mathrm{LV}$ pressure ratio after PDA stenting.

\section{Follow-up after PDA Stenting}

The infants were monitored for features of heart failure in the next 48 hours after the procedure and discharged home after 2 days. Heparinization was continued for 24 hours and aspirin $(3 \mathrm{mg}$. $\left.\mathrm{kg}^{-1} \cdot \mathrm{d}^{-1}\right)$ and clopidogrel $\left(1 \mathrm{mg} \cdot \mathrm{kg}^{-1} \cdot \mathrm{d}^{-1}\right)$ orally were started immediately after the procedure. Echocardiographic LV assessment was repeated at weekly intervals. Two to 3 weeks later, once the LV was found to be prepared by echocardiography, ASO was performed after discontinuing antiplatelet drugs. ${ }^{5}$

\section{ASO: Surgical Procedure of Stent Removal}

After single right atrial, venous, and aortic cannulation, the stented duct and branch PA were dissected and looped. Cardiopulmonary bypass was initiated after snaring the branch PA. ASO proceeded in routine fashion with transection of the aorta and excision of coronary buttons. While the main PA was being transected, the aorta was clamped beyond the left subclavian artery with reduced flows to maintain selective cerebral perfusion. The ductal stent was removed and the ductus divided between ligatures. Subsequent steps of medial flap door-based reimplantation of coronary buttons, Lecompte maneuver, reconstruction of the neoaorta and neo-PA, and closure of the foramen ovale under brief deep hypothermic circulatory arrest were similar to conventional ASO. Duration of bypass, clamp, and arrest time were noted.

\section{Postoperative Course}

Each infant's course in the postoperative care unit was monitored for duration of ventilation, need for inotropic agents, duration of intensive care unit stay, duration of total hospital stay, and serial echocardiographic assessment of LV function.

\section{Results}

Among 65 ASO procedures done in the period from 2003 to 2006, 33 patients had TGA-IVS and 16 of them were older than 1 month on presentation. Primary arterial switch in these late presenters in our initial experience was characterized by morbid low cardiac output, low systemic pressures, anuria, and pulmonary edema and managed by prolonged ventilatory assistance and hypertonic peritoneal dialysis in our center. To avoid this morbidity, ductal stenting strategy to retrain the LV was conceptualized recently and done on 2 patients in the last 7 months. Both these patients with TGA-IVS and regressed LV presented with severe cyanosis 
TABLE 1. Echocardiographic details and hemodynamic data

\begin{tabular}{|c|c|c|c|c|}
\hline & \multicolumn{2}{|c|}{ Patient 1} & \multicolumn{2}{|c|}{ Patient 2} \\
\hline Age/weight & \multicolumn{2}{|c|}{$3 \mathrm{mo} / 3.6 \mathrm{~kg}$} & \multicolumn{2}{|c|}{$3 \mathrm{mo} / 3.8 \mathrm{~kg}$} \\
\hline $\mathrm{SaO}_{2}(\%)$ & \multicolumn{2}{|c|}{$60 \%$} & \multicolumn{2}{|c|}{$55 \%$} \\
\hline LV appearance & \multicolumn{2}{|c|}{ Banana shaped } & \multicolumn{2}{|c|}{ Banana shaped } \\
\hline LV FW thickness & \multicolumn{2}{|c|}{$2.8 \mathrm{~mm}$} & \multicolumn{2}{|c|}{$2.7 \mathrm{~mm}$} \\
\hline Indexed LVEDV & \multicolumn{2}{|c|}{$7 \mathrm{~mL} / \mathrm{m}^{2} \mathrm{BSA}$} & \multicolumn{2}{|c|}{$8.1 \mathrm{~mL} / \mathrm{m}^{2} \mathrm{BSA}$} \\
\hline LV FS $(\%)$ & \multicolumn{2}{|c|}{$28 \%$} & \multicolumn{2}{|c|}{$31 \%$} \\
\hline Indexed LV mass & \multicolumn{2}{|c|}{$18 \mathrm{~g} / \mathrm{m}^{2} \mathrm{BSA}$} & \multicolumn{2}{|c|}{$19.8 \mathrm{~g} / \mathrm{m}^{2} \mathrm{BSA}$} \\
\hline Status of PDA & \multicolumn{2}{|c|}{ Tiny PDA dilated/stented } & \multirow{2}{*}{\multicolumn{2}{|c|}{$\begin{array}{l}\text { Fully closed PDA, recanalized } \\
4 \times 10 \mathrm{~mm} \text { coronary stent } †\end{array}$}} \\
\hline Stent used & \multicolumn{2}{|c|}{$3.5 \times 8 \mathrm{~mm}$ coronary stent ${ }^{*}$} & & \\
\hline Hemodynamics & Pre-PDA stent & Post-PDA stent & Pre-PDA stent & Post-PDA stent \\
\hline RV systolic pressures & $110 \mathrm{~mm} \mathrm{Hg}$ & $90 \mathrm{~mm} \mathrm{Hg}$ & $130 \mathrm{~mm} \mathrm{Hg}$ & $78 \mathrm{~mm} \mathrm{Hg}$ \\
\hline LV systolic pressures & $44 \mathrm{~mm} \mathrm{Hg}$ & $75 \mathrm{~mm} \mathrm{Hg}$ & $44 \mathrm{~mm} \mathrm{Hg}$ & $47 \mathrm{~mm} \mathrm{Hg}$ \\
\hline Pressure LV/RV & 0.4 & 0.83 & 0.34 & 0.6 \\
\hline Oxygen saturations & $50 \%$ & $90 \%$ & $55 \%$ & $88 \%$ \\
\hline
\end{tabular}

$\mathrm{SaO}_{2}$, Oxygen saturations; $L V$, left ventricle; $F W$, free-wall thickness; $L V E D V$, left ventricular end-diastolic volume; $m^{2} B S A$, body surface area in square meters; $F S$, fractional shortening; $P D A$, patent ductus arteriosus; $R V$, right ventricle. *3.5-mm diameter, 8-mm long stent; $\dagger 4$-mm diameter, 10 -mm long stent.

at 3 months of age. Table 1 details their demographic characteristics and echocardiographic indices. The echocardiographic LV free wall thickness, LV mass, and squashed appearance served as noninvasive indicators for low LV pressures. Both patients had restrictive atrial septal communication and low resting oxygen saturations.

\section{Cardiac Catheterization and PDA Stenting}

Both patients underwent balloon atrial septostomy and PDA stenting as described above. Their hemodynamic data are detailed in Table 1 . In both patients, the LV/RV pressure ratio was not favorable for planning a direct $\mathrm{ASO} .{ }^{10} \mathrm{PDA}$ stenting resulted in significant improvement of LV/RV pressure ratio (Figure 1).

\section{Postprocedural Echo Evaluation}

The changes in LV wall thickness, mass, and 2-dimensional echocardiographic appearances in both patients are shown in Table 2. The banana shape of the LV changed to normal (Figure 2). The bowing of interventricular septum into the LV on the short-axis view changed to normal (Figure 3). The LV free wall thickness and volumes on the parasternal long-axis view increased (Figure 4). In the second patient, even though acute hemodynamics after a 4-mm stent deployment in the PDA showed a $31-\mathrm{mm} \mathrm{Hg}$ pressure difference between the RV and LV, an echocardiogram after 2 weeks (Figure 5) demonstrated only a $12-$ to $15-\mathrm{mm} \mathrm{Hg}$ gradient between the aorta and PA across the stented PDA, which possibly indicated a further slow increase of the LV and PA pressures after the PDA stenting. This Doppler finding showed that ductal stenting offered a consistent pressure overload stimulus for inducing LV hypertrophy.

\section{Surgery and Postoperative Course}

ASO was undertaken after 24 and 28 days of PDA stenting in the 2 patients. In both patients, the stent could be removed from the PA after a post left subclavian aortic clamp and duct divided. The cardiopulmonary bypass times were 125 and 158 minutes in the 2 patients. The postoperative course was uneventful, with 3 days of mechanical ventilatory support and intensive care unit stay. Low-dose dopamine $\left(5 \mu \mathrm{g} \cdot \mathrm{kg}^{-1} \cdot \min ^{-1}\right)$ and milrinone $\left(0.6 \mu \mathrm{g} \cdot \mathrm{kg}^{-1}\right.$. $\min ^{-1}$ ) were used as inotropes for 3 days, and the 2 patients were discharged on eighth and tenth postoperative days.

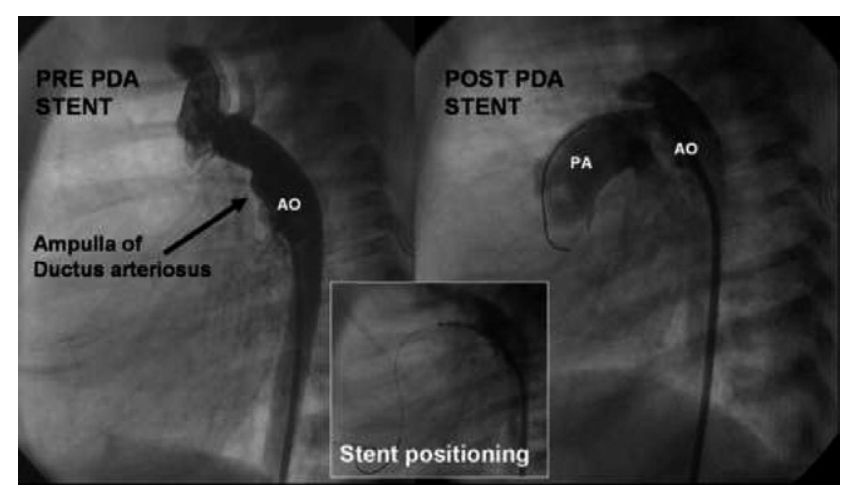

Figure 1. Lateral view aortogram shows ductal ampulla as a hump from the anterior wall of the aorta. Inset shows a guidewire advanced through the ductal ampulla into the pulmonary artery by recanalizing the closed ductus arteriosus and a short coronary stent positioned at the ductal level. On the right, after ductal stenting with a 4-mm balloon, aortic injection shows a good filling of the pulmonary arteries. Ao, Aorta; $P A$, pulmonary artery; $P D A$, patent ductus arteriosus. 
TABLE 2. Echocardiographic left ventricular indices before and after ductal stenting

\begin{tabular}{lcccc}
\hline & \multicolumn{2}{c}{ Patient 1 } & & \multicolumn{2}{c}{ Patient 2 } \\
\cline { 2 - 4 } & Pre-PDA stent & Post-PDA stent & Pre-PDA stent & Post-PDA stent \\
\hline LV FW thickness & $2.4 \mathrm{~mm}$ & $4.9 \mathrm{~mm}$ & $2.7 \mathrm{~mm}$ & $4.6 \mathrm{~mm}$ \\
LVEDV & $7 \mathrm{ml} / \mathrm{m}^{2} \mathrm{BSA}$ & $31 \mathrm{ml} / \mathrm{m}^{2} \mathrm{BSA}$ & $8.1 \mathrm{ml} / \mathrm{m}^{2} \mathrm{BSA}$ & $28 \mathrm{ml} / \mathrm{m}^{2} \mathrm{BSA}$ \\
LV mass & $18 \mathrm{~g} / \mathrm{m}^{2} \mathrm{BSA}$ & $101 \mathrm{~g} / \mathrm{m}^{2} \mathrm{BSA}$ & $19.8 \mathrm{~g} / \mathrm{m}^{2} \mathrm{BSA}$ & $116 \mathrm{~g} / \mathrm{m}^{2} \mathrm{BSA}$ \\
LV FS & $28 \%$ & $25 \%$ & $31 \%$ & $27 \%$ \\
\hline
\end{tabular}

$P D A$, Patent ductus arteriosus; $L V$, left ventricular; FW thickness, posterior free wall thickness in end-diastole; $L V E D V$, left ventricular end-diastolic volume; $m^{2} B S A$, body surface area in square meters; FS, fractional shortening.

Postoperative echocardiogram immediately after surgery showed good systolic function of the LV in both patients. The hemodynamics, urine output, wound healing, and the clinical condition of both patients remained satisfactory during the hospital stay. Follow-up echocardiogram at 6 months showed normal ventricular and neoaortic valve function.

\section{Discussion}

The optimal management of a patient presenting with TGAIVS beyond the first few weeks of life remains contentious, since the risk of ASO increases significantly beyond 3 to 4 weeks of age. This is attributed to failure of the LV to cope with systemic work beyond the first few weeks of life, because of preoperative deconditioning as pulmonary vascular resistance declines. ${ }^{11}$ The initially proposed 2-stage arterial switch, which was later modified by reducing the interval between stages, was put forward as a solution to patients presenting for surgery beyond the neonatal period. ${ }^{1,12}$ The interval between the stages in rapid 2-stage ASO is characterized by significant morbidity of prolonged ventilation, severe acidosis, low cardiac output state, extended inotropic support, and prolonged hospitalization. ${ }^{4}$ In many parts of

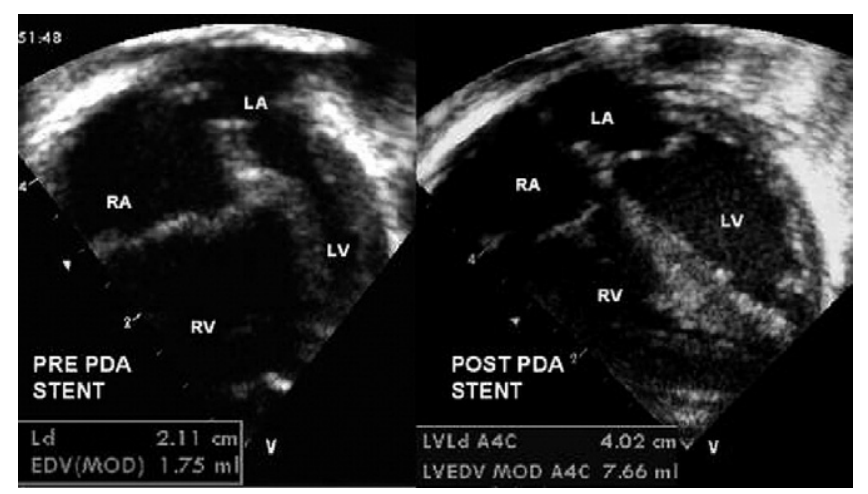

Figure 2. Apical 4-chamber echocardiographic view before and after ductal stenting. Before ductal stenting shown on the left, the regressed left ventricle has a banana shape, the interventricular septum bows into the left ventricle, and the left ventricular volumes are smaller than in the postductal stenting picture on the right. $L A$, Left atrium; $L V$, left ventricle; $R A$, right atrium; $R V$, right ventricle; $P D A$, patent ductus arteriosus. the world where late diagnosis of congenital heart disease is common and 95\% of infants go untreated, increased use of resources makes the 2-stage approach less appealing due to economic constraints. ${ }^{5}$ Despite the stormy postoperative course of the rapid 2-stage ASO, the high incidence of late-onset ventricular dysfunction, and atrial arrhythmias after Senning/Mustard surgery, the potential for improved preservation of systemic ventricular function with ASO became the most pressing reason for considering ASO rather than Senning surgery in infants presenting late. ${ }^{13}$

It is imperative that preparedness of the LV to support the high-pressure systemic circulation is mandatory for success of late ASO surgery. ${ }^{7} \mathrm{LV}$ mass index less than $35 \mathrm{~g} / \mathrm{m}^{2}$ is used as an indicator of need for LV "retraining," even in patients younger than 3 weeks of age. ${ }^{2}$ While rapid 2-stage ASO is the most widely followed technique of LV retraining, hemodynamic stress induced by PA banding is now recognized to lead to late ventricular myocardial dysfunction and increasing neoaortic regurgitation. ${ }^{6}$ Attempts made to retrain the LV by doing a Blalock-Taussig shunt alone,

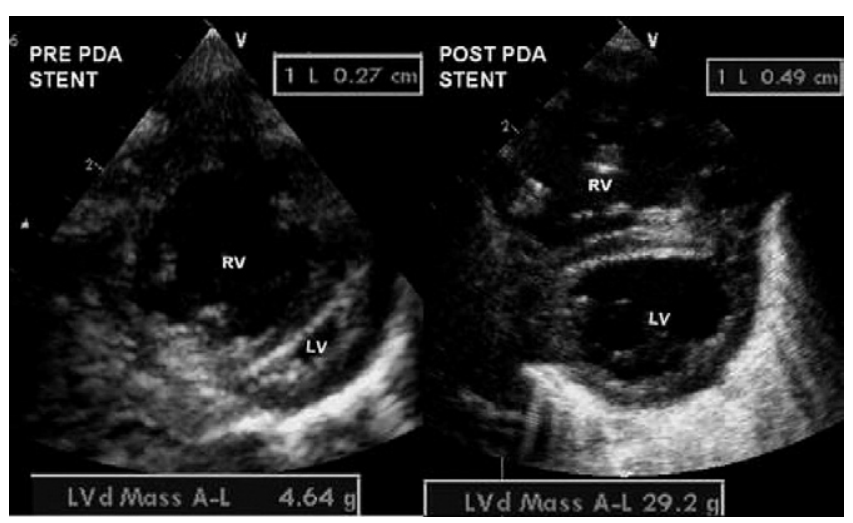

Figure 3. Parasternal short-axis echocardiographic view before ductal stenting on left shows that the left ventricular cavity has a crescent-shaped squashed appearance due to shifting of the interventriuclar septum to the left; after ductal stenting, shown on right, the left ventricle regains its normal shape. Increase of the left ventricular free wall thickness and mass after ductal stenting are also shown in the values. $L V$, Left ventricle; $R V$, right ventricle. 


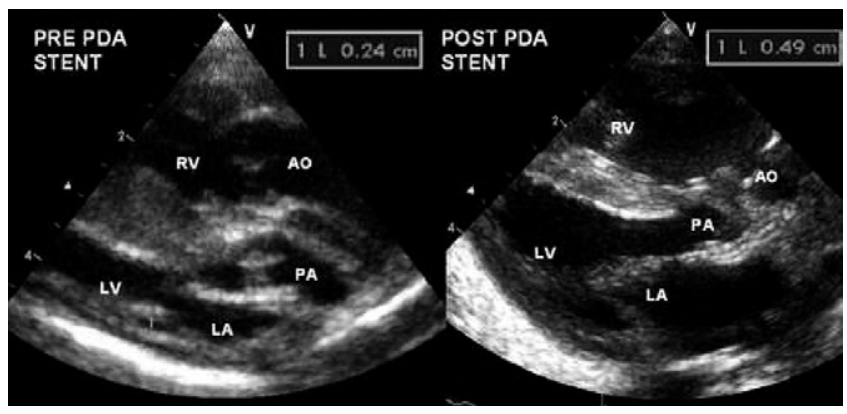

Figure 4. Parasternal long-axis echocardiogram shows improvement in left ventricular volumes and left ventricular free-wall thickness after ductal stenting (right) compared with before stenting (left). Ao, Aorta; $L A$, left atrium; $L V$, left ventricle; $P A$, pulmonary artery; $R V$, right ventricle; $P D A$, patent ductus arteriosus.

thereby avoiding the effects of the PA band (neoaortic regurgitation and late impaired ventricular mechanics), were not uniformly successful. ${ }^{14}$ A potential nonsurgical method of ventricular preparation by intermittent balloon occlusion of the main PA was reported in experimental animals, though it could not be translated to human practice. ${ }^{15}$

Here we report a nonsurgical option for retraining the LV by recanalizing and stenting the PDA. PDA stenting is an increasingly accepted mode of palliation in many cyanotic congenital heart diseases with reduced pulmonary blood flows, since the Blalock-Taussig shunt in early infancy is associated with higher morbidity such as diaphragmatic paralysis, pleural effusion, excessive pulmonary blood flow, and prolonged intensive care unit stay. 9,16 The procedural safety of PDA recanalization and stenting in these patients is proven in larger series, and use of 3.5- or 4-mm coronary stents instead of 5- to 6-mm stents is suggested as a measure to avoid postprocedural flooding of the lungs and heart failure. ${ }^{17,18}$ There is no previous literature on PDA stenting as a first stage of $\mathrm{LV}$ preparation (retraining) in infants presenting late with TGA-IVS and regressed, squashed LV. We conceptualized stenting PDA with 3.5- to 4-mm stents as a less-invasive means to increase the pulmonary blood flow in a controlled fashion and thus provide pressure and volume overload stimulus to the regressed LV. We monitored our patients after PDA stenting with serial echocardiography for PDA flows, LV volume, LV function, LV posterior wall thickness, mass, and geometry (shape). Both patients showed good PDA flows, significant increase in LV mass, posterior wall thickness, and ejection fraction, and favorable LV geometry developed in both. Contrary to the stormy hospital course of 2-stage ASO, the post-PDA stenting period was uneventful and both patients were discharged home after 48 hours without signs of heart failure. ${ }^{19}$

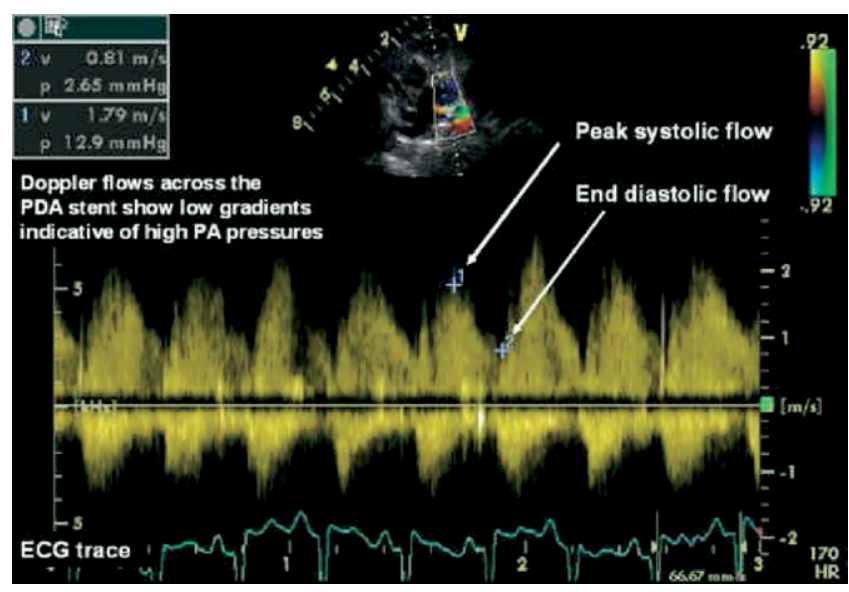

Figure 5. Pulse wave Doppler tracing across the stented duct shows low-velocity continuous flows from aorta to pulmonary artery, indicating that the pulmonary artery pressures are almost similar to aortic pressures. This proves that the ductal stent offers significant pressure overload to the left ventricle, to result in left ventricular retraining. PDA, Patent ductus arteriosus; ECG, electrocardiogram.

Similar to rapid 2-stage ASO, there was echocardiographic improvement in the ventricular thickness, mass, and volumes, and both patients underwent ASO with good results. The good ventricular systolic contractility on postoperative echocardiogram confirmed that the LV preparation was adequate with PDA stenting, which increases LV preload and afterload. Another major advantage of PDA stenting as a first stage, in our opinion, is avoiding thoracotomy and maintaining the virgin chest, simplifying definitive repair.

By adopting appropriate perioperative support, which includes use of LV assist devices, ASO is carried out as a primary procedure for patients up to the age of 2 months even if there is echocardiographic or catheter evidence of low LV pressures. ${ }^{8,20}$ The LV in older patients with TGAIVS might take longer to adapt to the acutely increased work after ASO, but there is a wide variation in the rate of preoperative LV deconditioning. The size of the interatrial communication and duct clearly influence LV preload and afterload, but other factors, possibly genetically predetermined, might also play a role in dictating the involution of pulmonary vascular resistance and LV performance. ${ }^{21}$ If the echocardiogram shows evidence of regressed LV, ASO in infants even under 2 months of age is still associated with prolonged ventilatory support and hospital stay, higher need for mechanical LV support, and delayed sternal closure. ${ }^{2}$ Before we adopted this PDA stenting strategy, our previous experience with direct ASO in late presenters was characterized by very low systemic pressures, prolonged ventilatory support, prolonged hypertonic peritoneal dialysis for 
anuria and pulmonary edema, and slow recovery of LV function over a period of 7 to 10 days. In developing countries that lack facilities for ventricular assist devices and extracorporeal membrane oxygenators, this prolonged intensive care management increased costs prohibitively and also predisposed to nosocomial sepsis, even leading to mortality. Both our patients were aged 3 months and presented with a squashed, banana-shaped LV. They could not be considered as possible straightforward candidates for primary ASO.

\section{Conclusions}

Our experience indicates that PDA stenting performed in the cardiac catheterization laboratory could be a viable, nonsurgical, less-invasive option of LV retraining in delayed presenters with TGA-IVS. Further studies are needed to test this hypothesis. Contrary to the increased incidence of neoaortic valve regurgitation induced by PA banding in the rapid 2-stage ASO, PDA stenting should not result in any mechanical disturbance of the neoaortic valve function. In the developing world that lacks facilites for ventricular assist devices and extracorporeal membrane oxygenator support, PDA stenting to retrain the LV simplifies ASO in late presenters. Since late studies after PA banding that poses acute stress of pressure overload show impairment of LV mechanics, long-term LV function after preparatory ductal stenting needs to be evaluated in the future. ${ }^{22}$

\section{References}

1. Yacoub MH, Radley-Smith R, Maclaurin R. Two-stage operation for anatomical correction of transposition of the great arteries with intact interventricular septum. Lancet. 1977;1:1275-8.

2. Lacour-Gayet F, Piot D, Zoghbi J, Serraf A, Gruber P, Mace L, et al. Surgical management and indication of left ventricular retraining in arterial switch for transposition of the great arteries with intact ventricular septum. Eur J Cardiothorac Surg. 2001;20:824-9.

3. van Doesburg NH, Bierman FZ, Williams RG. Left ventricular geometry in infants with d-transposition of the great arteries and intact interventricular septum. Circulation. 1983;68:733-9.

4. Wernovsky G, Giglia TM, Jonas RA, Mone SM, Colan SD, Wessel DL. Course in the intensive care unit after preparatory pulmonary artery banding and aortopulmonary shunt placement for transposition of the great arteries with low left ventricular pressure. Circulation. 1992;86(suppl 2):133-9.

5. Iyer KS, Sharma R, Kumar K, Bhan A, Kothari SS, Saxena A, et al. Serial echocardiography for decision making in rapid two-stage arterial switch operation. Ann Thorac Surg. 1995;60:658-64.

6. Colan SD, Boutin C, Castañeda AR, Wernovsky G, Status of the left ventricle after arterial switch operation for transposition of the great arteries: hemodynamic and echocardiographic evaluation. $J$ Thorac Cardiovasc Surg. 1995;109:311-21.

7. Boutin C, Jonas RA, Sanders SP, Wernovsky G, Mone SM, Colan SD. Rapid two stage arterial switch operation. Acquisition of left ventricular mass after pulmonary artery banding in infants with transposition of the great arteries. Circulation. 1994;90:1304-9.

8. Foran JP, Sullivan ID, Elliott MJ, de Leval MR. Primary arterial switch operation for transposition of the great arteries with intact ventricular septum in infants older than 21 days. J Am Coll Cardiol. 1998;31:883-9.

9. Michel-Behnke I, Akintuerk H, Thul J, Bauer J, Hagel KJ, Schranz D. Stent implantation in the ductus arteriosus for pulmonary blood supply in congenital heart disease. Catheter Cardiovasc Interv. 2004;61:242-52.

10. Nakazawa M, Oyama K, Imai Y, Nojima K, Aotsuka H, Satomi G, et al. Criteria for two staged arterial switch operation for simple transposition of great arteries. Circulation. 1998;78:124-31.

11. Norwood WI, Dobell AR, Freed MD, Kirklin JW, Blackstone EH Intermediate results of the arterial switch repair: a 20-institution study. J Thorac Cardiovasc Surg. 1988;96:854-63.

12. Jonas RA, Giglia T, Sanders SP, Wernovsky G, Nadal-Ginard B, Mayer JE Jr, et al. Rapid, two-stage arterial switch for transposition of the great arteries and intact ventricular septum beyond the neonatal period. Circulation. 1989;80(3 Pt 1):203-8.

13. Gewillig M, Cullen S, Mertens B, Lesaffre E, Deanfield J. Risk factors for arrhythmia and death after Mustard operation for simple transposition of the great arteries. Circulation 1991;84(5 Suppl):III187-92 .

14. Aoshima M, Yokota M, Shiraishi Y, Kyoku I, Kitano M, Shimada I, et al. The Blalock-Taussig shunt for simple complete transposition of the great arteries followed by later anatomic correction. Report of 2 cases with conflicting postoperative courses. J Cardiovasc Surg. 1986; 27:503-5.

15. Katayama H, Krzeski R, Frantz EG, Ferreiro JI, Lucas CL, Ha B, et al Induction of right ventricular hypertrophy with obstructing balloon catheter. Nonsurgical ventricular preparation for the arterial switch operation in simple transposition. Circulation. 1993;88(4 Pt 1):1765-9.

16. Tamisier D, Vouhé PR, Vermant F, Leca F, Massoat C, Neveux J. Modified Blalock-Taussig shunts: results in infants less than 3 months of age. Ann Thorac Surg. 1990;40:797-802.

17. Baslaim G. Effect of patent ductus arteriosus stenting on subsequent bidirectional Glenn anastomosis: a word of caution. J Thorac Cardiovasc Surg. 2006;131:e3-4.

18. Alwi M, Choo KK, Latiff HA, Kandavello G, Samion H, Mulyadi MD. Initial results and medium-term follow-up of stent implantation of patent ductus arteriosus in duct-dependent pulmonary circulation. J Am Coll Cardiol. 2004;44:438-45.

19. Corno AE, Hurni M, Payot M, Sekarski N, Tozzi P, von Segesser LK Adequate left ventricular preparation allows for arterial switch despite late referral. Cardiol Young. 2003;13:49-52.

20. Davis AM, Wilkinson JL, Karl TR, Mee RB. Transposition of the great arteries with intact ventricular septum: arterial switch repair in patients 21 days of age or older J Thorac Cardiovasc Surg. 1993;106:111-5.

21. Kang N, de Leval MR, Elliott M, Tsang V, Kocyildirim E, Sehic I, et al. Extending the boundaries of the primary arterial switch operation in patients with transposition of the great arteries and intact ventricular septum. Circulation. 2004;110(11 Suppl 1):II123-7.

22. Boutin C, Wernovsky G, Sanders SP, Jonas RA, Castenada AR, Colan SD. Rapid two stage arterial switch operation. Evaluation of left ventricular mechanics late after an acute pressure overload stimulus in infancy. Circulation. 1994;90:1294-303. 